\title{
SCAFFOLDING ACADEMIC LITERACY USING THE READING TO LEARN INTERVENTION: AN EVALUATIVE STUDY OF A TERTIARY EDUCATION CONTEXT IN SOUTH AFRICA
}

Tracey Millin \& Mark Millin

Stellenbosch University

This article reports on the use of the Reading to Learn (RtL) intervention at the University of KwaZulu-Natal (UKZN) to accelerate the development of academic literacy skills of illprepared students transitioning from school to university. This paper makes an original contribution to the literature on academic literacy development in three ways: firstly, this study pre-dates another published paper on the topic; secondly, it was the first study of RtL in a tertiary education context in South Africa and, thirdly, it applies a novel statistical method for data analysis purposes. The RtL pedagogy draws on the theoretical assumptions of Vygotsky, Halliday and Bernstein, and assists in the development of literacy (reading and writing) skills necessary to succeed at university. The context of education and poor literacy levels amongst primary, secondary and tertiary students in South Africa is briefly outlined, followed by a brief overview of RtL. The paper continues by adopting a small-scale quantitative approach to testing the efficacy of RtL. In addition to various descriptive statistics, the analysis of literacy scores, scores which were generated throughout an academic writing module at UKZN, is undertaken using a nonparametric testing procedure. A noteworthy finding of the study concerns the weakest cohort of students, in that, these students made the greatest improvements throughout the RtL intervention. Hence, RtL may be a useful mechanism to 'democratise' literacy classrooms by narrowing the abilities gap between students with weaker and stronger literacy skills in South Africa.

\section{Keywords}

English for academic purposes; scaffolding academic literacy; marginalised learners; reading to learn; genre pedagogy; nonparametric.

\section{INTRODUCTION}

'It [has] become increasingly clear [by] the weight of evidence support[ing] the conclusion that there is an on-going crisis in South African education, and that the current system is failing the majority of South Africa's youth' (Spaull, 2013a: 3). From the plethora of national and international comparative studies on education, there is no doubt that, in general terms, educational quality is still sorely lacking in the South African context. In a day-and-age of globalisation, comes the need to improve the quality of educational outcomes for a nation to remain globally competitive. However, improving the quality of educational outcomes is rarely translated to all of a nation's school- and university-going population, which raises concerns about the equality of quality educational outcomes - this is a matter of how best to organise teaching and learning opportunities in order to maximise the number of students who benefit from a quality education. In other words, in South Africa, there is a growing need to work towards attaining a more fair allocation of quality learning opportunities offered 
to students (Schleicher, 2006). However, despite considerable expenditure, together with ongoing efforts to improve pedagogic practices, literacy ${ }^{1}$ performances have hardly progressed. Therefore, it is no surprise that the South African educational system might be characterised as a 'high cost, high enrolment, yet low quality system' (Taylor, 2009: 12). Given the above description of schooling in South Africa, the authors are more concerned with the poor quality of secondary school education, and the ramifications thereof on opportunities for successful teaching and learning at university.

Given the above worrying description of schooling in South Africa, together with the realisation that tertiary institutions appear to be inheriting the deficiencies of the secondary schooling sector, literacy intervention strategies are needed to remedy the low literacy skills development of ill-qualified students transitioning to university (this is not a problem found amongst non-native speakers of English only, according to one of the author's experience of teaching English to learners from Grades 10, 11 and 12, and lecturing at university). Specialised support programmes are readily available at tertiary institutions across South Africa for students deemed 'at-risk' of not completing their studies. However, despite the programmes on offer, graduation rates remain low (Letseka \& Maile, 2008). It is for this reason that a specialised academic reading and writing programme, namely Reading to Learn (RtL), was chosen for implementation amongst undergraduate (first-, second- or third-year students were allowed to enrol) Social Science students at the Pietermaritzburg campus of the University of KwaZulu-Natal (UKZN) during the first semester of 2010. One of the authors was a co-lecturer on this module.

The paper comprises six parts. The first section gives a background to the study. The second section offers a rationale for the study by outlining the problem at hand and explaining why a study of this nature might be important in the context of tertiary education in South Africa. The third section gives a brief overview of the theoretical underpinnings of RtL, the efficacy thereof, and then contrasts RtL with the traditional academic cycle. The fourth section explains the data collection procedure, followed by a description of the data. The fifth section presents the test results and discusses some key findings from the analysis. The sixth section concludes the paper.

\section{BACKGROUND TO THE STUDY}

To elaborate on the quality of education in South Africa, recent global testing of Grade 4 learners' reading skills found that more than $75 \%$ of South African learners are performing well below international benchmarks (Unesco, 2011). Furthermore, of the 30 countries tested globally, South Africa produced the highest percentage of students scoring well below 'low levels' in reading skills, followed closely by Morocco, Qatar and Kuwait (Unesco, 2011). In sub-Saharan Africa, the Southern and Eastern Africa Consortium for Monitoring Educational Quality (SACMEQ) reported that approximately $25 \%$ of Grade 6 learners in South Africa had not developed basic reading and writing skills, whilst $40 \%$ of Grade 6 learners had developed basic reading and writing skills only (Taylor, 2008). South African students are out performed in reading skills by countries such as Kenya, Tanzania and Botswana. These countries are reported to have a gross domestic product (GDP) one tenth of South Africa's GDP, which illustrates that poverty should not necessarily be an excuse for poor levels of

\footnotetext{
${ }^{1}$ The term 'literacy' can be rather ambiguous. Therefore, for the purposes of this paper, the term will refer to a student's ability to read English texts fluently, with comprehension, and write English texts coherently, at an appropriate level to ensure access to higher learning (Unesco, 2011).
} 
literacy. It should come as no surprise to various stakeholders that, insofar as literacy skills are concerned, South Africa continues to lag behind countries with a similar political and economic standing, and continues to exhibit marked inequality in educational outcomes between schools.

\section{Figure 1: Distributional and Social Inequality in Sub-Saharan Africa}



Source: Hungi et al. (2010)

Figure 1 highlights a disturbing reality for education in South Africa. Of the 15 SACMEQ countries or ministries of education represented, South Africa has the widest distributional spread of reading performance by various socioeconomic and demographic characteristics. In other words, South Africa has the largest gap between better- and poorer-performing readers, with poverty-stricken students more likely to experience an inferior education. From an equity point of view, the status quo is disturbing, because the more impoverished a student is, the more likely it is that a better quality of education can positively influence the educational outcomes of said student. Access to quality education (for all) is the key to unlocking the cycle of poverty, but narrowing the distributional spread between students (see, for example, Mainland Tanzania) is only likely to occur if richer and poorer students alike have access to the same quality of education. Said differently, quality education for all students is needed to alleviate the problem of ill-prepared students entering the university system.

\section{RATIONALE FOR THE STUDY}

Social and educational transformation is enshrined by The Constitution of South Africa. However, it could be argued that educational transformation - literacy development being a key indicator thereof - has not happened as expected by various stakeholders (Howie et al., 2012; Van Schalwyk, 2008). One possible reason is the growing disjuncture between students' acquired versus their required academic literacy skills for enrolment at higher 
education institutions in South Africa. In other words, tertiary institutions require students to be able to independently learn from reading by the time they enter undergraduate studies. But, one can argue whether students have been able to acquire these necessary skills by the time they leave the secondary schooling system. In resolving this problem, there is a need to develop, assess and evaluate the efficacy of alternative pedagogic practices (for example, RtL being the focus of this study), that might be able to speedily raise the academic literacy levels amongst a burgeoning cohort of ill-prepared students transitioning into the tertiary education sector in South Africa.

Although there exists a plethora of empirical evidence establishing the relatively weak literacy performance amongst primary and secondary school-goers in South Africa (Howie et al., 2012; Spaull, 2013a; Spaull, 2013b), which has been generated by DBE systemic testing (e.g. Annual National Assessments or ANAs) and independent testing (e.g. Progress in International Reading Literacy Study or PIRLS), there is still, however, a dearth of research which investigates literacy performance amongst tertiary students. There are two reasons why a study of the RtL intervention is deemed important. Firstly, it appears that attempts have been made by universities to find alternative approaches to the development of academic literacy (reading and writing) skills, yet persistently low graduation rates may demonstrate that few have succeeded to date (Letseka \& Maile, 2008). Secondly, given that RtL may be offered as an alternative approach to academic literacy development, not much is known about the efficacy of RtL in a South African tertiary education context. Although WildsmithCromarty and Steinke (2014) offer a study of RtL at UKZN (but within the Commerce Faculty), the research reported within this paper offered the first known study of RtL for a tertiary education context in South Africa (see Millin, 2011). Ipso facto, this paper makes an original contribution to our understanding of RtL in a South African context.

In an effort to test the efficacy of RtL within a South African context the study seeks to analyse students' changing literacy scores, as proxied by their scores achieved for various written tasks as part of a process-based approach to academic literacy development. A process-based approach to literacy development requires students to write multiple drafts (assignments) for each task, for which comprehensive commentary is given to assist students with improving their academic writing skills. RtL was used for the duration of the Effective Writing for the Social Sciences module at the Pietermaritzburg campus of UKZN during the first semester of 2010. First- to third-year undergraduate students were enrolled in the module. The primary purpose of the study is to investigate to what extent RtL, as applied to the tertiary education context of UKZN, was as effective as previous research in Australia has shown. In doing so, the study uses a small-scale quantitative approach to data analysis, by adopting a nonparametric (or distribution-free) testing procedure. Apart from being appropriate to analysing data in the behavioural sciences, another strength of nonparametric techniques is 'that they do not assume that the scores under analysis were drawn from a population distributed in a certain way, e.g., from a normally distributed population' (Siegel, 1956: vii). This is clearly the case in the present study, in which little is known about the behaviour of the population under investigation.

\section{A BRIEF OVERVIEW OF READING TO LEARN ${ }^{2}$}

The RtL intervention was originally developed to address the unsatisfactory literacy performance of indigenous Australian learners for both educational access and success,

\footnotetext{
${ }^{2}$ The theoretical foundations of RtL, and the practical realisation within literacy classrooms, are extensive and are too broad for the scope of this paper. For more detailed readings of RtL, please consult the following website which contains a bank of resources about RtL: http://www.readingtolearn.com.au/ 
where academic reading and writing skills were deemed to be of greatest importance. The conceptual framework underpinning this methodology is borne out of the seminal work of three key educational theorists and the predominant themes of their work, namely: learning is a social process (Vygotsky, 1978); language is a text which needs to be located within a specific social context (Halliday, 1978; 1989, 1996) and education is a pedagogic discourse which may maintain inequality (Bernstein, 1975; 1990; 1996). RtL offers a top-down approach to academic literacy development beginning with the text as a whole unit (discourse semantics), followed by an analysis at the sentence level (lexico-grammar) and ending with an analysis at the individual word level (graphology) (Millin, 2011). Furthermore, RtL draws heavily on Genre Pedagogy (Martin \& Rose, 2005) and Systemic Functional Grammar (Halliday, 1994).

RtL attempts to combine different aspects of numerous academic literacy pedagogies, resulting in an educational methodology that may be able to fast track development of students' academic literacy skills (Rose, 2005; Acevedo, 2010; Millin, 2011). Several studies undertaken in contexts other than South Africa have demonstrated that RtL is effective in improving academic literacy skills (McRae et al., 2000; Rose \& Acevedo, 2006; Acevedo, 2010). In addition, research has also revealed that the smaller (weaker) the students' literacy base, the greater the literacy gains, thereby, democratising the classroom (Rose, 2005; Rose \& Acevedo, 2006; Rose et al., 2008; Millin, 2011). This is largely due to the fact that RtL's fundamental goal is to reallocate categories of consciousness that would generally be linked with middle class occupation, to societal groups marginalised by middle class pedagogic discourse and practices (Freire, 1971; Bernstein, 1990). In other words, RtL's goal is to eliminate educational oppression by making use of a methodology that is focused on assisting learners in the acquisition of crucial orientations to reading and writing, achieved by careful scaffolding in purposefully designed interactive cycles (Rose, 2006a; Millin, 2011). In reality, what this means in the current research context is that RtL assists ill-prepared students in overcoming barriers to teaching and learning at university by scaffolding them in how to read and write complex academic material.

Figure 2 highlights the inefficiency of current standard academic practices at universities. Given that the principal skill required for success at university is the ability to independently learn from reading (Rose et al., 2008), it stands to reason that students ill-equipped to independently learn from reading fail to access course content material, given the assumption that all learners will be able to access and understand, on their own, the vast array of readings prescribed outside of lectures. The university lecturer then merely synthesises the numerous readings, which he or she assumes have been read and comprehended independently, by offering advanced discussions in class related to course readings (Rose et al., 2008). Students unable to access course content material via course readings, struggle to transfer the knowledge acquired from prescribed texts into the written medium (class assignments), which is the primary method of assessing student learning at university level. The authors' experience is that, students who are already equipped with the skills to independently learn from reading, are only further advantaged by the traditional academic cycle, leaving already disadvantaged students even further behind, which can lead to student attrition or high dropout rates amongst the weaker cohort of students. In other words, the traditional academic cycle in Figure 2 exacerbates the chasm between students from advantaged versus disadvantaged school backgrounds. 
Figure 2: The Traditional Academic Cycle

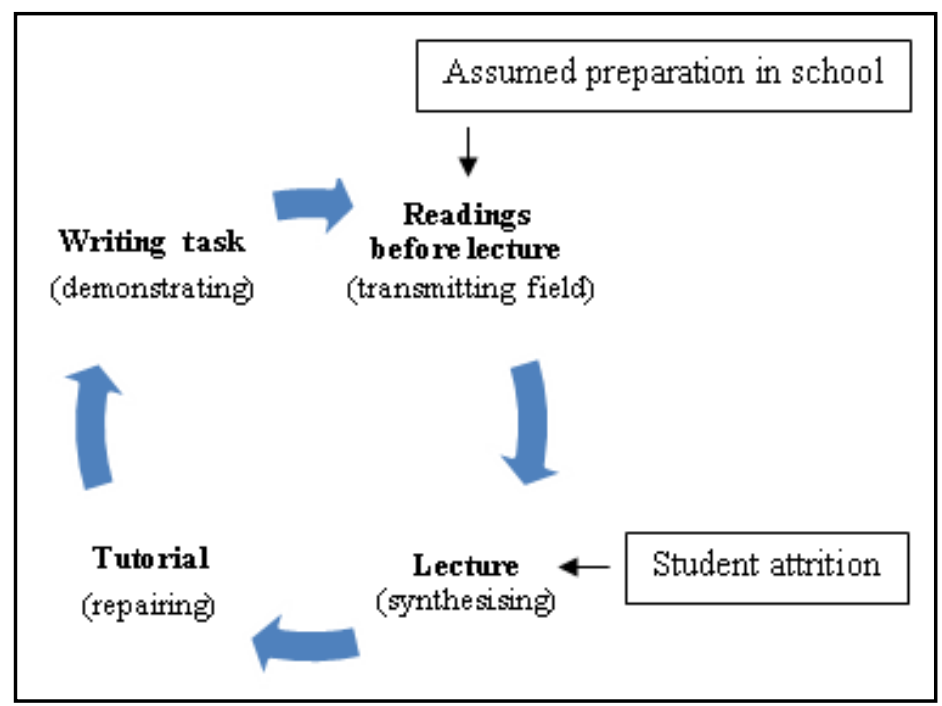

Source: Rose et al. (2008)

In order to remedy the barriers to learning imposed upon previously disadvantaged learners by the traditional academic cycle, Rose et al. (2008) offer an alternative approach to teaching and learning by way of the scaffolded academic cycle (see Figure 3). Instead of assuming students are able to spend their time outside of class or lectures accessing course content through the reading of academic texts themselves, some class time is utilised to assist students in understanding how to access information from academic texts to ensure reading for comprehension is developed. In the same way, some class time is used to scaffold learners through the writing process. This process does not necessarily need to be the responsibility of a subject specialist lecturer, but could be taught by an academic literacy tutor or lecturer.

\section{Figure 3: The Scaffolded Academic Cycle}



Source: Rose et al. (2008) 
The scaffolded academic cycle's stages form the basis for the development of the six-stage RtL cycle (see Figure 4), which can be used in literacy support classrooms to improve students' literacy skills. Very briefly, the following activities take place within each stage of the RtL cycle (Rose, 2006b):

1. Preparing before Reading - students are oriented to the global meaning of the text, which includes an orientation to the genre and field of the text. This gives students background information concerning what the text is about, making the reading process easier.

2. Detailed Reading - students are offered intensive support during this stage by drawing attention to genre patterns, academic terminology, as well as language devices used to create meaning such as lexical and grammatical cohesive devices.

3. Preparing before Writing - students are given time to brainstorm synonyms for words highlighted during the detailed reading stage. This could be in a group activity format or a whole class format, with students taking turns to transcribe the class discussion on the board. The collated views are then used as a guide for the joint reconstruction stage.

4. Joint Reconstruction - students start to rewrite the text offered as a model by using the synonyms and ideas discussed during the preparing before writing stage.

5. Individual Reconstruction - intensive feedback is given to guide the individual rewrite.

6. Independent Writing - students make use of comments given during the joint reconstruction stage to write a final paper for submission.

\section{Figure 4: The Six-Stage Reading to Learn Cycle}

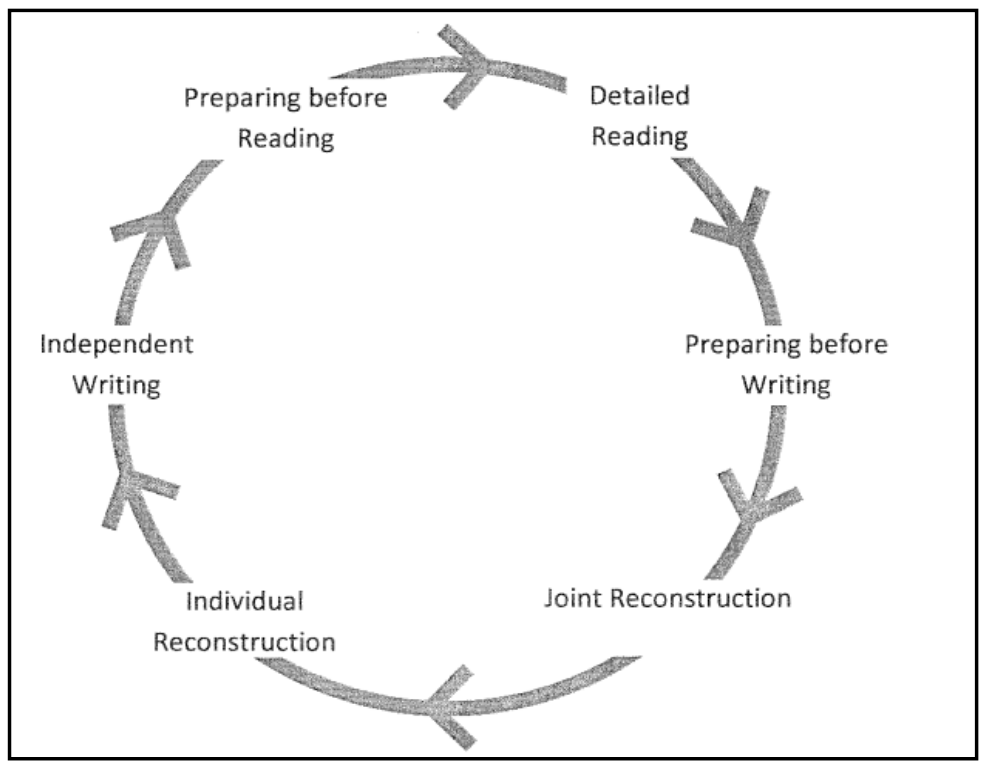

Source: Rose (2006b)

In summary, what we learn from a brief review of RtL is that it comprises a process (or cycle) through which students move, which scaffolds students from a place of being lessequipped to being better-equipped with the necessary academic literacy skills needed to succeed in various tasks. Although RtL focuses on reading for meaning, improving one's written abilities is the outcome of the process. The same aforementioned cycle is applied to the learning of various types or genres of writing. In theory, one would expect a steady or 
consistent improvement in students' written literacy skills over different assignments and tasks. The study seeks to test this hypothesis.

\section{DATA COLLECTION AND DESCRIPTION OF THE DATA}

The population of students under investigation were all undergraduate Social Science students, (ranging from first-year to third-year students all registered for a three-year degree), at the Pietermaritzburg campus of UKZN who voluntarily registered for the academic writing module in 2010. The module was advertised during the registration process at the beginning of the academic year, and offered students from under-resourced schools (largely quintile 1 to 4 schools) additional support for their upcoming academic studies. Of the roughly 133 Social Science students comprising 10 groups, who registered for the module, 51 students comprising 4 groups, were randomly selected for analysis purposes. The sample size of 51 students was a random selection, because students were allocated to groups on the basis of the alphabetical ordering of their surname. The study comprises a small-scale, longitudinal quantitative investigation of students' literacy scores in determining the efficacy of the RtL intervention. In other words, the performance of a random sample (cross-section) of students was analysed over a number of written submissions (time series). This gives rise to a smallscale micro panel of data, which was used for analysis purposes.

Table 1: Description of the Data Collection Procedure

\begin{tabular}{lccc}
\hline & Assignment or Test & $\begin{array}{c}\text { Formative } \\
\text { Assessment }\end{array}$ & $\begin{array}{c}\text { Summative } \\
\text { Assessment }\end{array}$ \\
\hline Diagnostic & Assignment 1 & & $\checkmark$ \\
\hline \multirow{2}{*}{ Task 1 } & Assignment 2 & $\checkmark$ & \\
& Assignment 3 & $\checkmark$ & \\
& Assignment 4 & & $\checkmark$ \\
\multirow{2}{*}{ Task 2 } & Assignment 5 & $\checkmark$ & \\
& Assignment 6 & $\checkmark$ & $\checkmark$ \\
\hline \multirow{2}{*}{ Tests } & Assignment 7 & & $\checkmark$ \\
& Test 1 & & $\checkmark$ \\
\hline
\end{tabular}

Table 1 describes the data collection procedure. Seven assignments and two tests were administered. Students' scores or marks on a number of formative and summative assessments throughout the semester were used for analysis purposes. In addition to a diagnostic or baseline assessment - to gauge the initial level of written literacy performance for each student, two separate process-based writing tasks and two tests were set for this module. Both Task 1 and Task 2 required students to compose an extended piece of writing located within the academic argument genre. Task 1 made use of an academic argument text to model genre conventions and specific language patterns found within an academic argument. However, Task 2 offered a recount type text, which exhibited a more conversational style of language usage (extracted from the You magazine), and required students to convert the text into an academic argument. Given that the course was designed to scaffold academic literacy skills, the language skills required in Task 2 were arguably more demanding than those required in Task 1. 
Both Task 1 and Task 2 included two drafts (formative assessment) and a final draft (summative assessment). Two further summative pieces of assessment were completed under test-type conditions. Therefore, a total of nine pieces of written work were assessed (i.e. 7 assignments and 2 tests). To clarify, students were asked to submit a written essay during the first week of term one, which formed the diagnostic form of assessment (Assignment 1). Once levels of literacy skills were established, the first task was developed. During the remaining weeks of term one, students worked on two separate drafts (Assignments 2 and 3) of their Task 1, culminating in a final draft (Assignment 4). A similar process was followed for Task 2 during term two of the first semester. The RtL intervention was run over two terms or one academic semester only. Given that a process-based approach was used, all assignments during terms one and two built upon knowledge learnt from each preceding assignment. For the purposes of this paper, reference is only made to the 7 assignments and not the 2 tests, because of reasons related to comparability of assessment. All formative and summative assessments were graded using the same standardised marking rubric. As far as possible, and for purposes of internal validity, the scores analysed were independently moderated in order to establish marking consistency across all students taking the module.

Table 2: Descriptive Statistics

\begin{tabular}{l|c|ccc|ccc}
\hline & A1 & A2 & A3 & A4 & A5 & A6 & A7 \\
\hline Mean & 72.70 & 67.64 & 70.41 & 78.27 & 71.08 & 70.37 & 70.15 \\
Std Dev.* & 7.763 & 5.138 & 6.541 & 7.256 & 8.317 & 9.421 & 7.040 \\
Median & 74 & 68 & 71 & 80 & 72 & 71 & 70 \\
IQR** & 12 & 8 & 9 & 8 & 12 & 15 & 11 \\
Min. & 58 & 54 & 55 & 62 & 56 & 48 & 56 \\
Max. & 92 & 78 & 82 & 90 & 88 & 85 & 82 \\
\hline $\mathbf{N}$ & 47 & 50 & 49 & 51 & 39 & 43 & 39 \\
\hline
\end{tabular}

Notes: *Refers to standard deviation. ${ }^{* *}$ Refers to interquartile range, and is the difference between the values for the $75^{\text {th }}$ and $25^{\text {th }}$ percentiles. ' $A$ ' refers to the respective assignment. ' $N$ ' refers to the sample size.

Table 2 shows the descriptive statistics for each piece of assessed work. Several noteworthy observations can be made. Firstly, the mean or median scores or marks show a steady improvement for Task 1 (A2, A3 and A4), but no improvement for Task 2 (A5, A6 and A7), contrary to expectation. Secondly, although the absolute level of the mean or median scores are rather high for each assignment, the analysis which follows is most concerned with the relative scores (the change in scores) by taking into consideration the difference in a student's performance from one piece of assessment to another. Thirdly, the descriptive statistics only tell part of the story, and are only useful to give a broad idea of the aggregate data patterns throughout the intervention, but in themselves, are not enough to show the significance (or insignificance) of sample (assignment) comparisons. Hence, the next section starts by briefly outlining the paired samples (matched-pairs) test to be used to compare students' performance across different assignments as part of a process-based approach to academic literacy development. In the analysis and discussion which follows, although reference has been made to mean (average) and median (middle) scores in Table 2 - for the interested reader to compare, reference will be made solely to median scores, because these are a better measure of central tendency in distribution-free samples. 


\section{ANALYSIS AND DISCUSSION}

The analytical results which follow were generated using the Wilcoxon (matched-pairs) signed-rank test. The parametric equivalent of this test is the dependent or paired samples ttest. However, the Wilcoxon test allows for greater flexibility of statistical analysis. In other words, in statistical parlance, the Wilcoxon test is more robust (less susceptible) to violations in the distributional assumptions so important in parametric testing procedures - in layman's terms, under varying distributional properties and small sample sizes, the Wilcoxon test is more powerful at discerning the 'truth' in the data (see, for example, Posten, 1982). Although the method of analysis is not new, its application to the problem at hand (assessing academic literacy development) is novel. For a detailed explanation of the Wilcoxon test, the interested reader is referred to Wilcoxon (1945) and Siegel (1956: 75-83).

Table 3: Wilcoxon Signed-Rank Test Results

\begin{tabular}{l|ccccccc}
\hline & \multicolumn{7}{|c}{ Pairwise Comparisons } \\
& A3-A2 & A4-A3 & A6-A5 & A7-A6 & A4-A1 & A7-A4 & A7-A1 \\
\hline Z Statistic & -2.555 & -4.705 & -0.331 & -0.746 & -3.868 & -4.090 & -3.038 \\
P-value (2-tailed) & 0.011 & 0.000 & 0.740 & 0.456 & 0.000 & 0.000 & 0.002 \\
No. Negative Ranks & 16 & 7 & 19 & 15 & 8 & 30 & 26 \\
No. Positive Ranks & 29 & 41 & 14 & 20 & 34 & 7 & 5 \\
Mean Negative Rank & 18.22 & 18.50 & 15.74 & 17.97 & 17.88 & 20.75 & 15.48 \\
Mean Positive Rank & 25.64 & 25.52 & 18.71 & 18.03 & 22.35 & 11.50 & 18.70 \\
Sum of Negative Ranks & 291.50 & 129.50 & 299 & 269.50 & 143 & 622.50 & 402.50 \\
Sum of Positive Ranks & 743.50 & 1046.50 & 262 & 360.50 & 760 & 80.50 & 93.50 \\
Ties & 3 & 1 & 2 & 1 & 4 & 1 & 5 \\
\hline N & 48 & 49 & 35 & 36 & 46 & 38 & 36 \\
\hline
\end{tabular}

Table 3 presents the test results. The various pairwise comparisons are given in the header row of the table. The key finding is that the first half of the RtL intervention (Task 1) generally showed a consistent improvement in students' written literacy performance in that the comparisons A3-A2 and A4-A3 were statistically significant (i.e. meaningfully different pairwise performances). These results are supported by the median descriptive statistics (see Table 2) for A2 (68\%), A3 (71\%) and A4 (80\%), which show a progressive improvement. The comparison A4-A1 also shows that, collectively, many more students improved in their written abilities by the end of the first half of the intervention versus their initial diagnostic or baseline assessment. The results from the abovementioned pairwise comparisons support the hypothesised expectation for the first half of the RtL intervention, and thus compare favourably with previous findings from the Australian context.

However, the second half of the RtL intervention (Task 2) did not reveal a significant improvement, contrary to expectation, most likely because of a greater balance between positive and negative differences in performance over comparisons A6-A5 and A7-A6. This result (see Table 3) is supported by a stagnation in the median for A5 (72\%), A6 (71\%) and A7 (70\%) (see Table 2). Possible reasons for the mixed performances in the second half of the programme are beyond the scope of this paper, and will be discussed as part of a forthcoming paper. However, some reasons for the relatively poorer performance may be related to the level of complexity of course material in the second half of the module (Task 
2 ); the type of teaching strategies used as the module deviated from RtL pedagogic practices somewhat with Task 2; the type of texts used in the second half of the intervention and a more constrained timeframe for completion of the intervention. The marginal downward trend of students' assignment marks for Task 2, might offer an interesting critique of pedagogic practices used to scaffold academic writing.

A very interesting result is given by the comparison A7-A1 (comparison between the final submission for Task 2 and the diagnostic assessment). The number and sum of negative ranks is greater than the number and sum of positive ranks (26 and 402.50 versus 5 and 93.50, respectively). However, the mean positive rank (18.70) is greater than the mean negative rank (15.48). Considering that only 5 students had a positive difference, whereas 26 students had a negative difference, one can conclude that these 5 students had rather large improvements in their written abilities, when comparing pre- and post-intervention scores. For instance, 3 of these 5 students started the module with roughly the poorest academic writing skills, but completed the module with the greatest gains of all students, ranging between 11 and 14 percentage points. The Wilcoxon test is useful in highlighting this result. A more in-depth qualitative inquiry of these 5 students ('splitting' the data) might be warranted in order to discover what led to them making such marked improvements in their written literacy abilities. This is a good example of where quantitative and qualitative research methods might best be used symbiotically to uncover and interpret data patterns.

\section{CONCLUSION}

According to recent national and international testing of literacy levels (Taylor, 2008; Unesco, 2011; Spaull, 2013a \& 2013b), the inequality of education offered at both a primary and secondary school level in South Africa highlights the deficiency of the schooling system to adequately prepare all learners, regardless of socioeconomic circumstances, for tertiary studies. This paper focused on the inequality of literacy skills amongst undergraduate students at UKZN as opposed to focusing on English language proficiency, per se, because unequal preparation for university studies is often a major stumbling block for universities, like UKZN, which have to remedy deficiencies in the required skills for university study, inherited from the schooling system. For this reason, the RtL intervention was chosen for evaluation as it is an academic literacy development programme designed to scaffold all students, and especially weaker students, resulting in a catch-up effect. The RtL intervention was incorporated into an academic writing module at UKZN during the first semester of 2010, and offered intensive scaffolding in academic writing. A sample of 51 out of roughly 133 students enrolled in the module were chosen to take part in the study.

In general terms, the RtL intervention showed a statistically significant improvement in students' demonstration of their written literacy abilities over the first half of the intervention, but no meaningful difference in students' performance over the second half of the intervention, contrary to what one might expect from an intensive process-based approach to writing, like RtL, where students' literacy abilities should improve consistently throughout the intervention. The findings over the first half of the module do offer some form of validation for the claims made by David Rose (see Rose et al., 2008: 14-17) that RtL can aid in the development of academic literacy skills at university. However, with regards to the counter-intuitive results found in the second half of the module, some possible reasons were advanced, which are to be discussed in a forthcoming paper. What this study showed was that some of the weaker (or weakest) students, who voluntarily enrolled in the academic writing 
programme, were able to make the greatest gains versus other students who started the intervention with a better base of written literacy skills. This finding implies that RtL might be useful for equalising differences in written literacy abilities between students over time, which is particularly important in classroom contexts, such as those found in South African education today, where a diverse range of written literacy skills exists.

The findings of this study may offer some hope for students from poorer education backgrounds - students who enter the university system ill-prepared - if universities invest in interventions, like RtL, to remedy said deficiencies. However, given the small sample nature of this study, we exercise caution in making grandiose generalisations to all other contexts. We recommend that future research should be geared towards collecting larger samples of data in different university contexts, and that such quantitative data should ideally be supplemented with qualitative data, which profiles students' linguistic historiographies. Furthermore, it is recommended that the RtL intervention be investigated over a longer period of time, such as two semesters (or one academic year), as was the case with previous research of RtL undertaken in Australia.

\section{REFERENCES}

ACEVEDO, C. 2010. Will the implementation of reading to learn in Stockholm schools accelerate literacy learning for disadvantaged students and close the achievement gap? Sweden: Multilingual Research Institute.

BERNSTEIN, B. 1975. Class and pedagogies: Visible and invisible. London: Routledge.

BERNSTEIN, B. 1990. The structuring of pedagogic discourse. London: Routledge.

BERNSTEIN, B. 1996. Pedagogy, symbolic control and identity: Theory, research, critique. London: Taylor and Francis.

FREIRE, P. 1971. Unusual ideas about education. Paris: Unesco.

HALLIDAY, M. 1978. Language as a social semiotic. London: Arnold.

HALLIDAY, M. 1989. Spoken and written language. Oxford: Oxford University Press.

HALLIDAY, M. 1994. An introduction to functional grammar. London: Arnold.

HALLIDAY, M. 1996. On grammar and grammatics. In Hasan, R, D Butt \& C Cloran (Eds), Functional descriptions. Amsterdam: Benjamins.

HOWIE, S, S VAN STADEN, M TSHELE, C DOWSE \& L ZIMMERMAN. 2012. PIRLS 2011:

South African childrens' reading literacy achievement. Pretoria: Centre for Evaulation and Assessment, University of Pretoria.

HUNGI, N, D MAKUWA, M SAITO, S DOLATA, F VAN CAPPELLE, L PAVIOT \& J VELLIEN. 2010. SACMEQ III Project results: Pupil achievements levels in reading and mathematics. Southern and Eastern Africa Consortium for Monitoring Educational Quality. (Working Document 1.). In UNESCO, 2011. The hidden crisis: Armed conflict and education, Paris: Unesco Publishing.

LETSEKA, M \& S MAILE. 2008. High university drop-out rates: A threat to South Africa's future: HSRC Policy Brief, Pretoria: Human Sciences Research Council.

MARTIN, J \& D ROSE. 2005. Designing literacy pedagogy: Scaffolding assymmetries. In: WEBSTER, J, C MATTHIESSEN \& R HASAN. (Eds.) Continuing discourse on language. London: Equinox: 251-280.

McRAE, D, G AINSWORTH, J CUMMINGS, P HUGHES, T MACKAY \& K PRICE. 2000. What has worked and will work again: The IESIP strategic results project. Australian Curriculum Studies Association.

MILLIN, T. 2011. Scaffolding academic literacy with undergraduate social science students at the University of KwaZulu-Natal using the learning to read: reading to learn intervention strategy: An evaluative study. Unpublished Masters Dissertation, University of Edinburgh. 
POSTEN, H. 1982. Two-sample Wilcoxon power over the Pearson system and comparison with the ttest. Journal of Statistical Computation and Simulation, 16(1): 1-18.

ROSE, D. 2005. Democratising the classroom: A literacy pedagogy for the new generation. Journal of Education, 37(1): 131-168.

ROSE, D. 2006a. Literacy and equality in the classroom. Future directions in literacy. Available from www.edsw.usyd.edu.au/schools teachers/prof dev/index.shtml [Accessed: 25/07/2014]

ROSE, D. 2006b. Literacy and social responsibility: Training teachers to teach reading across the curriculum. Sydney: University of Sydney.

ROSE, D \& C ACEVEDO. 2006. Closing the gap and accelerating learning in the middle years of schooling. Literacy Learning: The Middle Years, 14(2): 32-45.

ROSE, D, M ROSE, S FARRINGTON \& S PAGE. 2008. Scaffolding academic literacy with indigenous health sciences students: An evaluative study. Journal of English for Academic Purposes, 7(3): 165-179.

SCHLEICHER, A. 2006. The economics of knowledge: Why education is key for Europe's success. Lisbon Council Policy Brief, 1(1): 1-17. Available from http://www.lisboncouncil.net/publication/publication/46.html [Accessed: 26/01/2015].

SIEGEL, S. 1956. Nonparametric statistics for the behavioural sciences. London: McGraw-Hill.

SPAULL, N. 2013a. South Africa's education crisis: The quality of education in South Africa 1994 2011. Johannesburg: Centre for Development and Enterprise.

SPAULL, N. 2013b. Poverty \& privilege: Primary school inequality in South Africa. International Journal of Educational Development. 33: 436-447.

TAYLOR, N. 2008. What's wrong with South African schools? Johannesburg: JET Educational Services.

TAYLOR, N. 2009. The state of South African schools part 1: Time and regulation of consciousness. Journal of Education, 46: 9-32.

UNESCO, 2011. The hidden crisis: Armed conflict and education, Paris: Unesco Publishing.

VAN SCHALKWYK, S. 2008. Acquiring academic literacy: A case of first-year extended degree programme students at Stellenbosch University. Stellenbosch: Unpublished Doctoral Dissertation.

VYGOTSKY, L. 1978. Mind in society. Cambridge, MA: Harvard University Press.

WILCOXON, F. 1945. Individual comparisons by ranking methods. Biometrics Bulletin, 1(6): 80-83.

WILDSMITH-CROMARTY, R \& K STEINKE. 2014. The write approach: Can R2L help at tertiary level? Per Linguam, 30(1): 38-54

\section{BIOGRAPHICAL NOTE}

Tracey Millin is currently a full-time, third-year, Doctoral candidate at the University of Stellenbosch in the Department of General Linguistics. She has a special interest in Emancipatory Education and Educational Linguistics and hopes to focus her research on the effects of specialised literacy interventions in an effort to eradicate educational inequality in South Africa. She currently teaches part-time on the PGCE programme at Stellenbosch University. She completed her undergraduate studies at the University of KwaZulu-Natal, and was given the opportunity to read for a Masters degree in Education at The University of Edinburgh in 2010/2011. Email address: millintracey@gmail.com

Mark Millin is currently a full-time, second-year Doctoral candidate at the University of Stellenbosch, South Africa, in the Department of Economics. His research interests are in the field of The Economics of Education - global public spending on education patterns and literacy development. Mark previously lectured undergraduate Economics at the University of Natal/KwaZulu-Natal, South Africa from 2003-2013. After completing his Masters in Economics in 2003, he went on to complete a Postgraduate Certificate in Education in 2008, and was afforded the opportunity of reading for a Masters in Education at The University of Edinburgh in 2010/2011. Email address: markmillin@gmail.com 